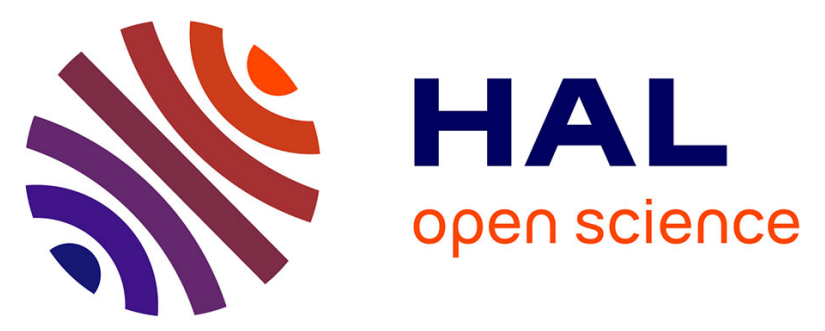

\title{
Asymmetric Intramolecular Hydroamination of Alkenes in Mild and Wet Conditions-Structure and Reactivity of Cationic Binuclear Gold(I) Catalysts
}

Marc-Antoine Abadie, Xavier Trivelli, Florian Medina, Frédéric Capet, Pascal Roussel, Francine Agbossou-Niedercorn, Christophe Michon

\section{To cite this version:}

Marc-Antoine Abadie, Xavier Trivelli, Florian Medina, Frédéric Capet, Pascal Roussel, et al.. Asymmetric Intramolecular Hydroamination of Alkenes in Mild and Wet Conditions-Structure and Reactivity of Cationic Binuclear Gold(I) Catalysts. ChemCatChem, 2014, 6 (8), pp.2235 - 2239. 10.1002/cctc.201402350 . hal-01717864

\section{HAL Id: hal-01717864 \\ https://hal.science/hal-01717864}

Submitted on 2 Jan 2022

HAL is a multi-disciplinary open access archive for the deposit and dissemination of scientific research documents, whether they are published or not. The documents may come from teaching and research institutions in France or abroad, or from public or private research centers.
L'archive ouverte pluridisciplinaire HAL, est destinée au dépôt et à la diffusion de documents scientifiques de niveau recherche, publiés ou non, émanant des établissements d'enseignement et de recherche français ou étrangers, des laboratoires publics ou privés. 


\title{
Asymmetric intramolecular hydroamination of alkenes in mild and wet conditions - structure and reactivity
}

\section{of cationic binuclear gold(I) catalysts}

\author{
M. -A. Abadie, X. Trivelli, F. Medina, F. Capet, P. Roussel, F. Agbossou-Niedercorn* and C. Michon*[a]
}

Abstract. Selected diphosphine binuclear gold(I) chloride complex was combined with a silver salt to catalyse efficiently for the first time the asymmetric intramolecular hydroamination of alkenes with high conversions and enantioselectivities, in mild conditions and in presence of water. Both enantiomers of the products could be obtained by controlling the molecular ion-pairs through the solvent polarity. The gold(I) cationic active species was characterized for the first time unambiguously at the solid state by X-ray analysis and in solution by DOSY $1 \mathrm{H}$ NMR experiments. No contribution of silver chloride was observed on the bonding mode of the catalyst.

The hydroamination of unactivated alkenes is the shortest synthetic route to secondary and tertiary amines. ${ }^{[1]}$ For the enantioselective synthesis of optically pure amines, the most studied and privileged hydroamination method is metalcatalysis. ${ }^{[1 c, 2-6]}$ Along the past years, the usefulness of gold was pointed out on various $\mathrm{C}-\mathrm{C}$ multiple bond substrates like alkynes, alkenes, allenes, and dienes for both intra- and intermolecular hydroamination reactions. ${ }^{[7]}$ Because high temperatures, long reaction times and strict conditions are generally required, gold catalysed hydroamination of alkenes has been scarcely studied in its asymmetric version. ${ }^{[7,8]}$ To the best of our knowledge, only four specific reports were published so far. First, binuclear gold(I) catalysts were found to be active for intermolecular hydroamination of ethylene and 1-alkenes with cyclic ureas leading to high yields and enantioselectivities. ${ }^{\left[{ }^{8 d]}\right]}$ Second, binuclear gold(I) species catalysed intramolecular hydroamination of $\mathrm{N}$-alkenyl ureas at room temperature with good yields and average enantioselectivities. ${ }^{[8 c]} A$ third work reported on the preparation and the use of several monodentate axially-chiral $\mathrm{N}$-heterocyclic carbene and phosphine ligands for mononuclear gold(I) catalyzed intramolecular hydroamination of $\mathrm{N}$-alkenyl tosylates. Moderate yields and enantioselectivities were obtained at quite high temperatures and reaction times. ${ }^{[8 b]}$ Finally, following our ongoing interest on hydroamination reaction, ${ }^{[9]}$ we recently reported on mononuclear and binuclear gold(I) complexes and found phosphoramidite ligands were leading to valuable catalysts for intramolecular hydroamination of several alkenes at mild temperatures, with good conversions and average enantioselectivities. ${ }^{[8 a]}$ Like many organometallics, most of gold complexes required the combined use of silver salts to be

[a] M. -A. Abadie, F. Medina, Dr. F. Capet, Dr. P. Roussel, Dr. F. Agbossou-Niedercorn, Dr. C. Michon

Unité de Catalyse et de Chimie du Solide, UCCS

CNRS, UMR 8181, Université Lille Nord de France

59655 Villeneuve d'Ascq (France)

Fax: (+) 33-320436585

E-mail: francine.agbossou@ensc-lille.fr, christophe.michon@ensclille.fr

[b] Dr. X. Trivelli

Laboratoire de Glycobiologie Structurale et Fonctionnelle, LGSF,

CNRS, UMR 8576, Université Lille Nord de France

Université Lille Nord de France

59655 Villeneuve d'Ascq Cedex, France

Supporting information for this article is available free of charge on the web activated. Indeed, reactive gold cationic species can be generated by abstraction of halides from neutral complexes. However, the existence of these so-called "naked gold complexes" [AuL] is still discussed for lack of structural proofs as isolable and well-defined species. ${ }^{[10,11 c]}$ Recent works have reported on the influence of silver salts on gold catalysed reactions. ${ }^{[11]}$ Impact on conversions and selectivities were observed and the interference of silver and chloride has been highlighted by several bonding modes for cationic monomeric and oligomeric phosphine gold chloride complexes (Scheme 1, $A$ to D). ${ }^{[11 d, 12]}$ Herein, we report on the combination of a binuclear gold(I) chloride complex and a silver salt to catalyse efficiently asymmetric intramolecular hydroamination of alkenes in mild and wet conditions, without any silver chloride effect on the bonding mode of the catalyst.<smiles></smiles>

A

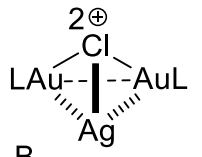

B<smiles>[GeH2]=[GeH2]</smiles>

C

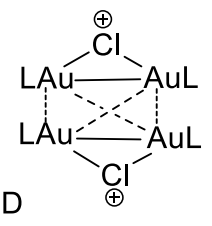

Scheme 1. Bonding modes of gold chloride complexes.

Our study started by screening several diphosphine ligands within earlier optimized reaction conditions. ${ }^{[\mathrm{Ba}]}$ We found the best catalyst arose from DTBM-Segphos phosphine ligand. Though monocationic binuclear complexes were shown to be preferred in the case of the intramolecular hydroalkoxylation of allenes, ${ }^{[13]}$ we found dicationic binuclear gold complexes were much more active and selective for the intramolecular hydroamination of alkenes (see Scheme 2 and the Supporting Information). Additional screenings confirmed toluene was the best non-polar solvent and perchlorate was the best anion (see the Supporting Information). Control experiments proved the reaction was not catalysed by $\mathrm{AgClO}_{4}$ itself. However, addition of the silver salt at last, ${ }^{[11 c]}$ when the gold chloride complex was premixed with the substrate, lowered significantly the conversion and slightly the enantioselectivity. The same trend was observed when catalyst was filtered through a PTFE filter (see the Supporting Information). Hence, at this stage, an effect of silver chloride on the hydroamination reaction and on the catalyst could not be excluded. Interestingly, the addition of water to the reaction mixture improved significantly yields and 


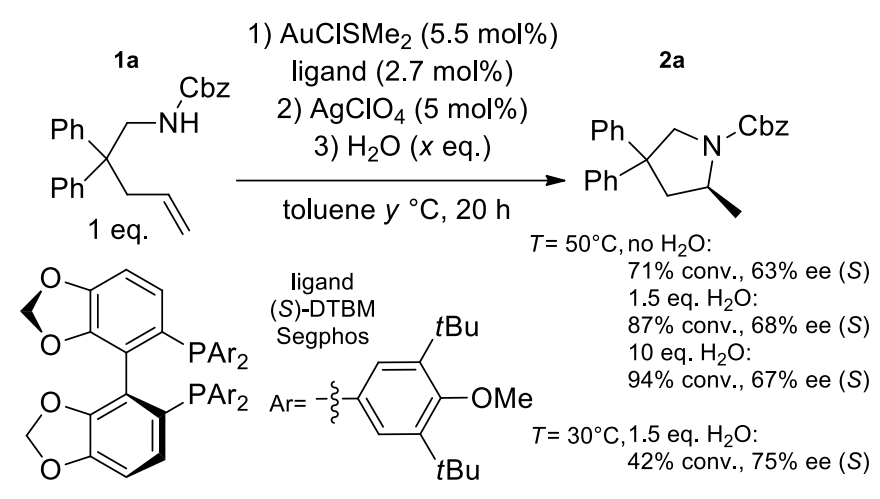

Scheme 2. First results

to a lesser extent enantioselectivities. In order to check if the dicationic gold(I)-perchlorate catalyst was likely to be hydrolysed, ${ }^{[14]}$ we followed by NMR the reaction of $\mathbf{1 a}$ with a stoichiometric amount of pre-formed gold complex. The latter displayed unchanged ${ }^{31} \mathrm{P}$ spectra along the reaction and no hydrate or hydroxide species could be observed through ${ }^{1} \mathrm{H}$ nucleus (see the Supporting Information). In addition, the presence of free protons in the reaction medium could be excluded because the use of a non-coordinative base like 2,6di-tert-butyl-pyridine or of a proton trap like $\mathrm{PhSi}(\mathrm{Me})_{3}$ did not have any effect on the reaction (see the Supporting Information). Considering the significance of toluene as a solvent for the hydroamination reaction, the role of anion- and cation- $\pi$ interactions ${ }^{[15,16]}$ between the catalyst and

toluene may be invoked in the light of previous results in the field of gold catalysis. ${ }^{[8,17]}$ Moreover, regarding the increase of the conversions and enantioselectivities upon addition of water in the reaction medium, the propensity of perchlorate salts to increase the surface tension of water and, at the meantime, to act as salting-in agents might contribute to a better solvation of catalyst and organic molecules. Indeed, according the Hofmeister series, perchlorate anion is a chaotrope acting through surface tension and direct ion binding. ${ }^{[18,19]}$ Though well known in enzymatic catalysis, ${ }^{[19 b, c]}$ such anion effect has been less studied in homogeneous catalysis using transition metals.

Scope and limitations of the catalyst were investigated (Table 1). Regarding the enantiomeric excess (ee), $\mathrm{N}$-alkenyl $\mathrm{CBz}$ substrate 1a led to the best results (entries 1-3). Though highest conversions and ee were obtained at $30^{\circ} \mathrm{C}$, the reaction proved to be faster at $50^{\circ} \mathrm{C}$ and remained quite selective. Surprisingly, by changing the solvent from toluene to methanol, we observed a reversal of enantioselectivity (entries 4,5 ). As reported by Toste et al., ${ }^{[20]}$ the use of an alcohol along with a cationic binuclear gold complex can generate an acidic species which catalysed the hydroamination reaction of 4,6-heptadienyl sulfonamides via a Brønsted acid catalysed pathway. In order to check such a possibility, we performed a series of reactions by adding 1.5 equivalent of an alcohol to the reaction mixture in toluene (see the Supporting Information). Depending on the nature of the alcohol used, the conversions were improved but no global trend could be observed.

Table 1. Substrate scope study.

1) $\mathrm{AuClSMe}_{2}(5.5 \mathrm{~mol} \%)$,

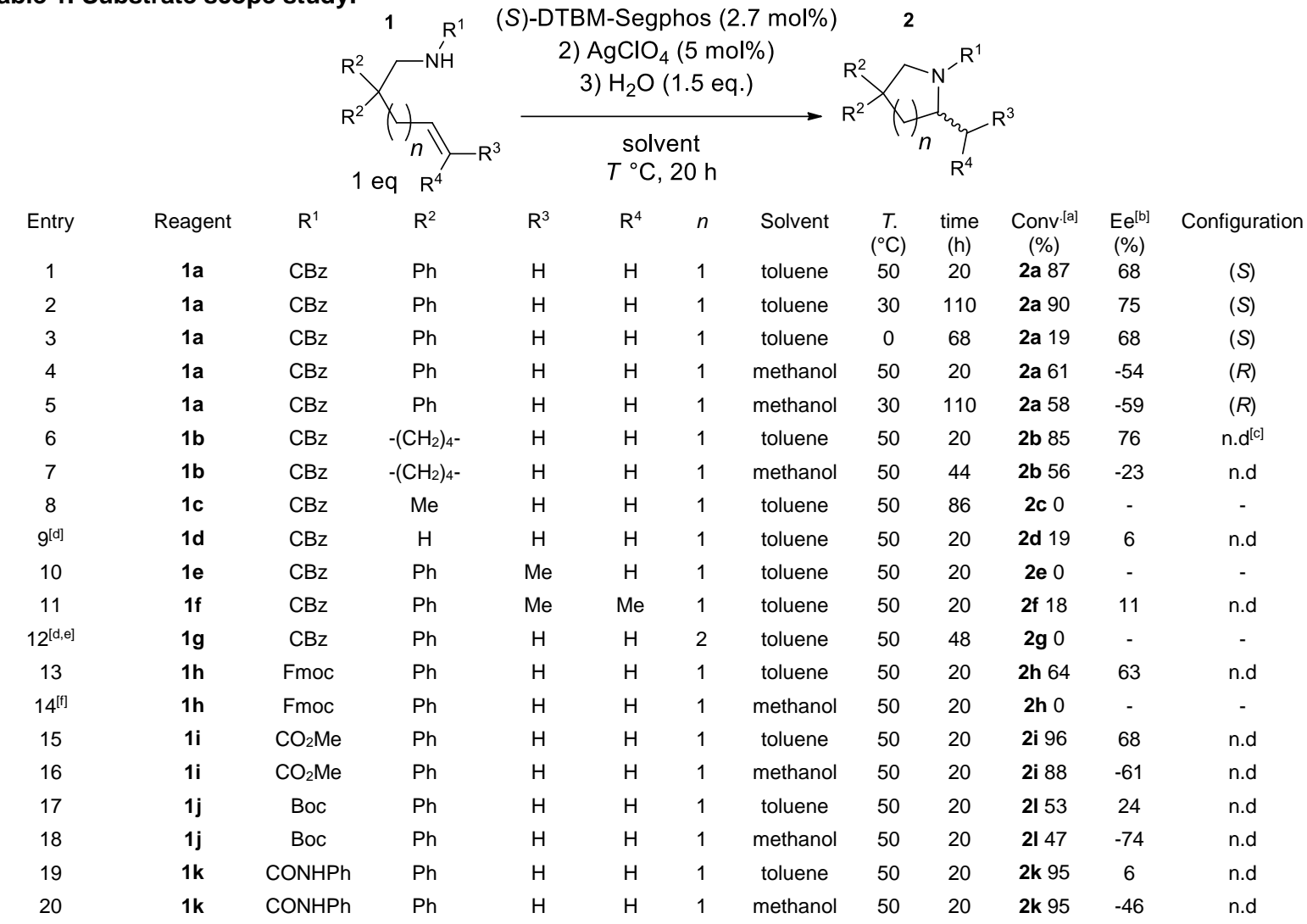

[a] From ${ }^{1} \mathrm{H}$ NMR. [b] From HPLC. [c] Not determined. [d] At $100^{\circ} \mathrm{C}$. [e] Same result in methanol. [f] Same result if no water added. 
Only the use of (+)-phenylethanol, (-)-menthol or methanol increased slightly the ee values to $67 \%$ ee whereas conversions were respectively 88,67 and $97 \%$. Finally, no hydroamination reaction of $1 \mathrm{a}$ could be observed in the presence of a catalytic amount of HOTf (see the Supporting Information). On the basis of these additional results, we concluded any Brønsted acid catalysis ${ }^{[20]}$ was unlikely. Beyond the simple solvent effect, the critical change in the reaction mechanism could arise from the weak molecular ion-pairs induced by the use of methanol. The latter already proved to act as a proton transfer agent ${ }^{[21]}$ like anions $\mathrm{do}^{[22]}$ (Scheme 3). Hence, the reaction started first by the nucleophilic attack which was previously found to be reversible. ${ }^{[23]}$ Second, the tautomerization of the resulting intermediate was assisted by the perchlorate. ${ }^{[22]}$ Finally, the stereochemical outcome of the hydroamination reaction appeared to be defined during the final protodeauration step ${ }^{[23]}$ by differentiation of the two diastereomeric intermediates depending on the solvent used (Scheme 3).

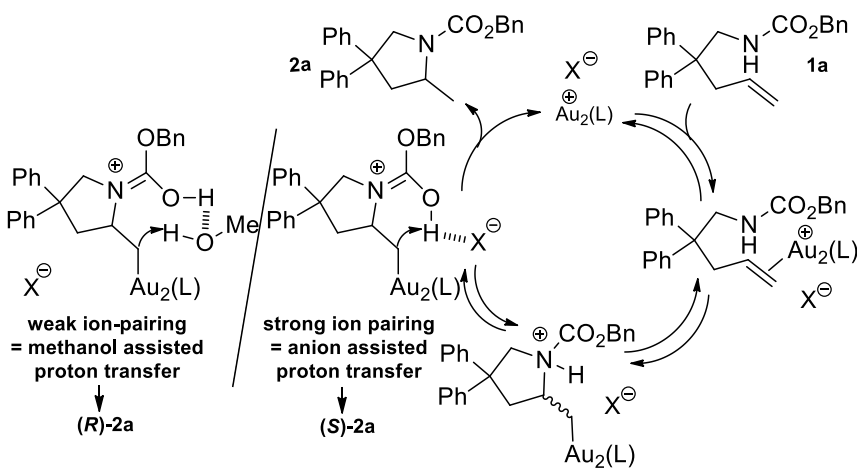

Scheme 3. Mechanistic proposal.

The change of substituents at the C2 position of the alkenyl chain had even a more critical effect on the reactivity and stereochemical outcome of the hydroamination reaction because of some Thorpe-Ingold effects (entries 6-9).[24] Indeed, at the exception of substrate $\mathbf{1 b}$, conversions and enantioselectivities were very low for reagents $1 \mathrm{c}$ and $\mathbf{1 d}$, respectively with methyl substituents and with a 5-hexenyl chain (entries 8, 9). In addition, amine reactivity proved to be sensitive to alkene substituents and ring size because substrates $\mathbf{1 e - g}$ didn't react well even within long reaction times (entries 10-12). Other substrates like $\mathrm{N}$-alkenyl Fmoc, and methylester $\mathbf{1 h}$ and 1i afforded good conversions and ee (entries 13-16). The reactivity of $N$-alkenyl Boc, and urea substrates, $1 \mathbf{j}$ and $\mathbf{1 k}$, was highly dependent of the solvent used. Best conversions and ee were obtained with methanol as a solvent (entries 17-20).

In order to define in solution the bonding mode of our cationic gold(I) species, DOSY ${ }^{1} \mathrm{H}$ NMR experiments were performed on gold complexes $3 \mathbf{a}-\mathbf{c}$ and palladium references 4a-b (Table 2). We found a good agreement between diffusion coefficient $\mathrm{D}$ and hydrodynamic radius $\mathrm{rH}$ of all species. This confirmed the presumed nuclearity and coordination of our catalysts and proved any chloride and/or silver bridged species $^{[11 c, d]}$ was unlikely. Indeed, compounds with higher molecular volumes and weights would have displayed lower diffusion coefficient $\mathrm{D}$ and higher hydrodynamic radius $\mathrm{rH}$.

At the solid state, the structure of gold catalyst $\mathbf{3 b}$ was confirmed by $\mathrm{X}$-ray diffraction analysis (Figure 1). The data were refined using a rigid body approach because tButyl substituents were disordered. Anions, i.e. tetrafluoroborate here, proved to be coordinated to the gold atoms which were not bond to each other. Hence, by using weakly coordinative anions like perchlorate and tetrafluoroborate, complexes $\mathbf{3 a - b}$ could be considered as neutral species like it was previously observed for other complexes with $\mathrm{NTf}_{2}$ anion. ${ }^{[25]}$ We measured for $3 \mathbf{b}$ a molecular radius of $8.989(19) \AA$ (see the Supporting Information) which was close from its $\mathrm{rH}$ value calculated from the DOSY ${ }^{1} \mathrm{H}$ NMR experiments. On the whole, we concluded no contribution of silver chloride was observed on the bonding mode of complexes $\mathbf{3 a - b}$.

Table 2. Results of DOSY ${ }^{1} \mathrm{H}$ NMR experiments.

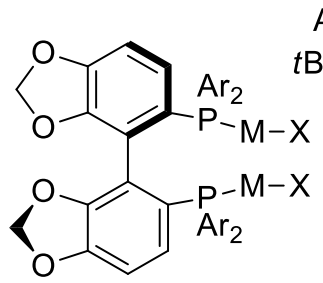

3a $(R) \mathrm{M}=\mathrm{Au}, \mathrm{X}=\mathrm{ClO}_{4}$ 3b $(R) \mathrm{M}=\mathrm{Au}, \mathrm{X}=\mathrm{BF}_{4}$ $3 \mathrm{c}(R) \mathrm{M}=\mathrm{Au}, \mathrm{X}=\mathrm{Cl}$<smiles>[X]c1cc(Br)c(OC)c(CC(C)(C)C)c1</smiles><smiles>[Mg][Mg]</smiles>

4a $(R) \mathrm{M}=\mathrm{Pd}, \mathrm{X}=\mathrm{ClO}_{4}$ 4b $(R) \mathrm{M}=\mathrm{Pd}, \mathrm{X}=\mathrm{Cl}$<smiles>[R17]c1ccc2c(c1-c1c([R11]([X])([Y20])[H])ccc3c1OCO3)OCO2</smiles>

\begin{tabular}{|c|c|}
\hline Compound & $D\left({ }^{1} H\right)\left(10^{-9} m^{2} s^{-1}\right)$ \\
\hline (S)-DTBM-Segphos & 5.03 \\
\hline (R) 3a & 4.98 \\
\hline (R) $3 \mathrm{~b}$ & 4.85 \\
\hline (R) $3 \mathrm{c}$ & 4.96 \\
\hline (R) $4 \mathrm{a}$ & 4.91 \\
\hline (R) $4 \mathrm{~b}$ & 4.96 \\
\hline
\end{tabular}

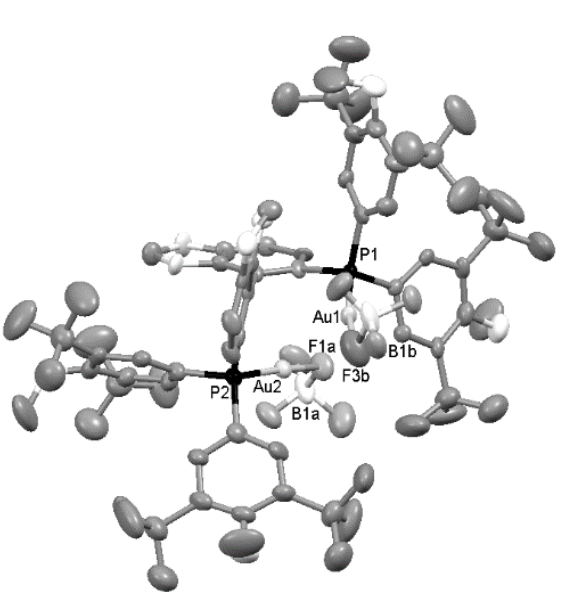

Figure 1. Molecular structure of catalyst $\mathbf{3 b}$ at the solid state. Thermal ellipsoids are shown at the $50 \%$ probability level. Hydrogens atoms and 2 molecules of toluene were omitted for clarity. Selected bond lengths $(\AA)$ : Au1Au2 4.390(19), P1-Au1 2.213(2), P2-Au2 2.205(2), Au1-F3b 2.101(15), Au2F1a 2.095(15). CCDC 995301. 
To summarize, when combined with silver perchlorate, a selected binuclear gold(I) chloride complex based on DTBMSegphos ligand catalysed efficiently for the first time the asymmetric intramolecular hydroamination of alkenes at mild temperatures in presence of water with high conversions and enantioselectivities. Both enantiomers of the products could be obtained by controlling the molecular ion-pairs through the solvent polarity. The involved binuclear gold(I) cationic catalyst which has been previously discussed for lack of structural proofs, was characterized unambiguously at the solid state by X-ray analysis and in solution by DOSY ${ }^{1} \mathrm{H}$ NMR experiments.

\section{Experimental Section}

Typical procedure for the substrate screening. In a glovebox, AuS $(\mathrm{Me})_{2} \mathrm{Cl}(0.01 \mathrm{mmol}, 2.95 \mathrm{mg})$ and (S)-DTBM-Segphos $(0.005 \mathrm{mmol}, 5.90 \mathrm{mg})$ are disposed in a first Schlenk flask. Under a nitrogen atmosphere, dry dichloromethane $(1 \mathrm{~mL})$ is then added and the resulting mixture is stirred for 1 hour at room temperature. Afterwards, the solvent is evaporated under vacuum and the resulting solid is dried 30 minutes before addition of $\mathrm{AgClO}_{4}(0.009 \mathrm{mmol}, 1.87 \mathrm{mg})$ in a glovebox. Under a nitrogen atmosphere, dry toluene $(1 \mathrm{~mL})$ is added and the resulting solution is stirred for 30 minutes before being transferred to a second Schlenk flask containing the corresponding substrate $(0.18 \mathrm{mmol})$. Finally, $\mathrm{H}_{2} \mathrm{O}(0.28 \mathrm{mmol}$, $5 \mu \mathrm{L})$ is added under nitrogen to the reaction mixture. After 20 hours under stirring at $50{ }^{\circ} \mathrm{C}$, the solution is filtered through a pad of silica gel using dichloromethane as solvent. After evaporation of solvents under vacuum, the resulting oil is analysed by ${ }^{1} \mathrm{H}$ NMR and HPLC.

\section{Acknowledgements}

We thank ANR (ANR-09-BLAN-0032-02 with a PhD fellowship to F.M), the French Ministry of Research and Higher Education (PhD fellowship to M.A.A), CNRS, Région Nord-Pas de Calais and FEDER (X-ray diffractometers, NMRs and other equipments) for financial support. We thank Mrs C. Méliet and C. Delabre (UCCS) for HPLC and elemental analyses, Mrs. N. Duhal (CUMA, Lille 2) for HRMS analyses.

Keywords: asymmetric catalysis $\bullet$ gold $\bullet$ hydroamination $\bullet$ alkene $\bullet$ phosphine ligands $\cdot$ silver

[1] a) J. J. Brunet, D. Neibecker, in Catalytic Heterofunctionalization from Hydroamination to Hydrozirconation, (Eds.: Togni, A.; Grutzmacher, H.), Wiley-VCH: Weinheim, Germany, 2001, pp. 10; b) S. Doye, in Science of Synthesis, Vol. 40a, (Eds.: Enders, D.; Schaumann, E.), Thieme: Stuttgart, 2009, pp. 241; c) J. Hannedouche, E. Schulz, Chem. Eur. J. 2013, 19, 4972; d) P. A. Dub, R. Poli, J. Am. Chem. Soc. 2010 132, 13799; e) U. M. Dzhemilev, G. A. Tolstikov, R. I. Khusnutdinov, Russ. J. Org. Chem. 2009, 45, 957; f) S. R. Chemler Org. Biomol. Chem. 2009, 7, 3009; g) T. E. Mueller, K. C. Hultzsch, M. Yus, F. Foubelo, M. Tada, Chem. Rev. 2008, 108, 3795; h) I. Aillaud, J. Collin, J. Hannedouche, E. Schulz, Dalton Trans. 2007, 36, 5105; i) K. C. Hultzsch, Adv. Synth. Catal. 2005, 347, 367; j) I. Bytschkov, S. Doye, Eur. J. Org. Chem. 2003, 935; k) T. E. Müller, M. Beller, Chem. Rev. 1998, 98, 675.

[2] For examples of asymmetric intramolecular hydroaminations with lanthanide complexes, see: a) Y. Chapurina, J. Hannedouche, J. Collin,
R. Guillot, E. Schulz, A. Trifonov, Chem. Commun. 2010, 46, 6918; b) A. L. Reznichenko, H. P. Nguyen, K. C. Hultzsch, Angew. Chem. 2010, 122, 9168; Angew. Chem. Int. Ed. 2010, 49, 8984; c) Y. Chapurina, H. Ibrahim, R. Guillot, E. Kolodziej, J. Collin, A. Trifonov, E. Schulz, J. Hannedouche, J. Org. Chem. 2011, 76, 10163; d) K. Manna, M. L. Kruse, A. D. Sadow, ACS Catal. 2011, 1, 1637; e) P. Benndorf, J. Jenter, L. Zielke, P. W. Roesky, Chem. Commun. 2011, 47, 2574; f) Y. Zhang, W. Yao, H. Li, Y. Mu, Organometallics 2012, 31, 4670; g) A. L. Reznichenko, K. C. Hultzsch, Organometallics 2013, 32, 1394.

[3] For examples of asymmetric intramolecular hydroamination with group 4 complexes, see: a) G. Zi, F. Zhang, L. Xiang, Y. Chen, W. Fang, H. Song, Dalton Trans. 2010, 39, 4048; b) A. L. Reznichenko, K. C. Hultzsch, Organometallics 2010, 29, 24; c) K. Manna, S. Xu, A. D. Sadow, Angew. Chem. 2011, 123, 1905; Angew. Chem., Int. Ed. 2011, 50, 1865; d) K. Manna, W. C. Everett, G. Schoendorff, A. Ellern, T. L. Windus, A. D. Sadow, J. Am. Chem. Soc. 2013, 135, 7235.

[4] For examples of asymmetric intramolecular hydroamination with maingroup metals, see: a) X. Zhang, T. J. Emge, K. C. Hultzsch, Organometallics 2010, 29, 5871; b) J. Deschamp, C. Olier, E. Schulz, R. Guillot, J. Hannedouche, J. Collin, Adv. Synth. Catal. 2010, 352, 2171; c) J. Deschamp, J. Collin, J. Hannedouche, E. Schulz, Eur. J. Org.Chem. 2011, 3329; d) J. S. Wixey, B. D. Ward, Chem. Commun. 2011, 47, 5449; e) J. Jenter, R. Köppe, P. W. Roesky, Organometallics 2011, 30, 1404; f) S. R. Neal, A. Ellern, A. D. Sadow, J. Organomet. Chem. 2011, 696, 228; g) X. Zhang, T. J. Emge, K. C. Hultzsch, Angew. Chem. 2012, 124, 406; Angew. Chem., Int. Ed. 2012, 51, 394; h) C. Brinkmann, A. G. M. Barrett, M. S. Hill, P. A. Procopiu, J. Am. Chem. Soc. 2012, 134, 2193; i) T. D. Nixon, B. D. Ward, Chem. Commun., 2012, 48, 11790.

[5] For examples of asymmetric intramolecular hydroamination with late transition metals, see: a) N. T. Patil, L. M. Lutete, H. Wu, N. K. Pahadi, I. D. Gridnev, Y. Yamamoto, J. Org. Chem. 2006, 71, 4270; b) X. Shen, S. L. Buchwald, , Angew. Chem. 2010, 122, 574; Angew. Chem. Int. Ed. 2010, 49, 564; c) B. W. Turnpenny, K. L. Hyman, S. R. Chemler, Organometallics 2012, 31, 7819.

[6] For examples of asymmetric intermolecular hydroaminations with late transition metals, see: a) L. Fadini, A. Togni, Chem. Commun. 2003, 39, 30; b) J. Zhou, J. F. Hartwig, J. Am. Chem. Soc. 2008, 130, 12220; c) M. Otsuka, H. Yokoyama, K. Endo, T. Shibata, Org. Biomol. Chem. 2012, 10, 3815; d) C. S. Sevov, J. Zhou, J. F. Hartwig, J. Am. Chem. Soc. 2012, 134, 11960; e) S. Pan, K. Endo, T. Shibata, Org. Lett. 2012, 14, 780; f) S. Zhu, N. Niljianskul, S. L. Buchwald, J. Am. Chem. Soc. 2013, 135, 15746; g) Y. Miki, K. Hirano, T. Satoh, M. Miura, Angew. Chem. 2013, 125, 13213; Angew. Chem. Int. Ed. 2013, 52, 10830; h) C. S. Sevov, J. Zhou, J. F. Hartwig, J. Am. Chem. Soc. 2014, 136, 3200 ; i) Y. Miki, K. Hirano, T. Satoh, M. Miura, Org. Lett., 2014, 16, 1498.

[7] About gold catalysis with C-C multiple bond substrates: a) M. Rudolph, A. S. K. Hashmi, Chem. Commun. 2011, 47, 6536; b) N. T. Patil, V. Singh, J. Organomet. Chem. 2011, 696, 419; c) R. A. Widenhoefer, Chem. Eur. J. 2008, 14, 5382; d) D. J. Gorin, B. D. Sherry, F. D. Toste, Chem. Rev. 2008, 108, 3351; e) A. S. K. Hashmi, Chem. Rev. 2007, 107, 3180.

[8] a) C. Michon, M.-A. Abadie, F. Medina, F. Agbossou-Niedercorn, Catalysis Today 2014, doi 10.1016/j.cattod.2014.01.030; b) Y. W. Sun, Q. Xu, M. Shi, Beilstein J. Org. Chem. 2013, 9, 2224; c) M. Kojima, K. Mikami, Synlett 2012, 23, 57; d) Z. Zhang, S. D. Lee, R. A. Widenhoefer, J. Am. Chem. Soc. 2009, 131, 5372.

[9] a) C. Michon, F. Medina, M.-A. Abadie, F. Agbossou-Niedercorn Organometallics 2013, 32, 5589; b) F. Medina, C. Michon, F. Agbossou-Niedercorn, Eur. J. Org. Chem. 2012, 6218; c) C. Michon, F. Medina, F. Capet, P. Roussel, F. AgbossouNiedercorn, Adv. Synth. Catal. 2010, 352, 3293.

[10] S. G. Weber, D. Zahner, F. Rominger, B. F. Straub, Chem. Commun. 2012, 48, 11325.

[11] About "silver effect" on gold catalysis: a) Y. Su; M. Lu, B. Dong, H. Chen, X. Shi; Adv. Synth. Catal. 2014, 356, 692; b) A. Guérinot, W. Fang, M. Sircoglou, C. Bour, S. Bezzenine-Lafollée, V. Gandon, Angew. Chem. 2013, 125, 5960 ; Angew. Chem. Int. Ed. 2013, 52, 5848; c) A. Homs, I. Escofet, A. M. Echavarren, Org. 
Lett. 2013, 15, 5782; d) Y. Zhu, C. S. Day, L. Zhang, K. J. Hauser, A. C. Jones, Chem. Eur. J. 2013, 19, 12264; e) D. Wang, R. Cai, S. Sharma, J. Jirak, S. K. Thummanapelli, N. G. Akhmedov, H. Zhang, X. Liu, J. L. Petersen, X. Shi, J. Am. Chem. Soc. 2012, 134, 9012; f) S. G. Weber, F. Rominger, B. F. Straub, Eur. J. Inorg. Chem. 2012, 2863; g) D. Weber, M. R. Gagné, Org. Lett. 2009, 11, 4962.

[12] a) S. G. Weber, F. Rominger, B. F. Straub, Eur. J. Inorg. Chem. 2012, 2863; b) K. Zhang, J. Prabhavathy, J. H. K. Yip, L. L. Koh, G. K. Tan, J. J. Vittal, J. Am. Chem. Soc. 2003, 125, 8452; c) H. Schmidbaur, A. Hamel, N. W. Mitzel, A. Schier, S. Nogai, Proc. Natl. Acad. Sci. USA 2002, 99, 4916; d) A. Hamel, N. W. Mitzel, H. Schmidbaur, J. Am. Chem. Soc. 2001, 123, 5106; e) A. Bayler, A. Bauer, H. Schmidbaur, Chem. Ber. 1997, 130, 115; f) R. Uson, A. Laguna, M. V. Castrillo, Synth. React. Inorg. Met.-Org.Chem. 1979, 9, 317.

[13] K. Aikawa, M. Kojima, K. Mikami, Adv. Synth. Catal. 2010, 352, 3131

[14] Y. Tang, B. Yu, RSC Adv. 2012, 2, 12686.

[15] About anion- $\pi$ interactions: a) Y. Zhao, C. Beuchat, Y. Domoto, J. Gajewy, A. Wilson, J. Mareda, N. Sakai, S. Matile, J. Am. Chem. Soc. 2014, 136, 2101; b) Y. Zhao, Y. Domoto, E. Orentas, C. Beuchat, D. Emery, J. Mareda, N. Sakai, S. Matile, Angew. Chem. 2013, 125, 10124; Angew. Chem. Int. Ed. 2013, 52, 9940; c) H. T. Chifotides, K. R. Dunbar, Acc. Chem. Res. 2013, 46, 894.

[16] About cation- $\pi$ interactions: a) D. A. Dougherty, Acc. Chem. Res. 2013, 46, 885; b) A. S. Mahadevi, G. N. Sastry, Chem. Rev. 2013, 113, 2100; c) S. Yamada, J. S. Fossey, Org. Biomol. Chem. 2011, 9,7275 .

[17] a) Q. Zhou, Y. Li, J. Am. Chem. Soc. 2014, 136, 1505; b) E. Herrero-Gómez, C. Nieto-Oberhuber, S. López, J. BenetBuchholz, A. M. Echavarren, Angew. Chem. 2006, 118, 5581; Angew. Chem., Int. Ed. 2006, 45, 5455.

[18] R. Breslow, T. Guo, Proc. Natl. Acad. Sci. USA. 1990, 87, 167.

[19] a) P. Lo Nostro, B. W. Ninham, Chem. Rev. 2012, 112, 2286; b) Z. Yang, J. Biotech. 2009, 144, 12; c) P. Bauduin, A. Renoncourt, D. Touraud, W. Kunz, B. W. Ninham, Current Opinion Colloid Interface Sci. 2004, 9, 43.

[20] O. Kanno, W. Kuriyama, J. Z. Wang, D. F. Toste, Angew. Chem. 2011, 123, 10093 ; Angew. Chem. Int. Ed. 2011, 50, 9919.

[21] a) C. M. Krauter, A. S. K. Hashmi, M. Pernpointner, ChemCatChem 2010, 2, 1226; b) J. Zhang, W. Shen, L. Li, M. Li, Organometallics 2009, 28, 3129 .

[22] G. Kovács, G. Ujaque, A. Lledós, J. Am. Chem. Soc. 2008, 130, 853.

[23] R. L. LaLonde, W. E. Brenzovich, D. Benitez, E. Tkatchouk, K. Kelley, W. A. Goddard III, F. D. Toste, Chem. Sci. 2010, 1, 226.

[24] a) A. Zulys, M. Dochnahl, D. Hollmann, K. Löhnwitz, J.-S. Herrmann, P. W. Roesky, S. Blechert, Angew. Chem. 2005, 117, 7972 ; Angew. Chem. Int. Ed. 2005, 44, 7794; b) J. Koller, R. G. Bergman, Chem. Commun. 2010, 46, 4577.

[25] N. Mezailles, L. Ricard, F. Gagosz, Org. Lett. 2005, 7, 4133. 
